\title{
FT-IR Investigation of Methoxy Substituted Benzenes Adsorbed on Solid Acid Catalysts
}

\author{
C. Lucarelli, ${ }^{\dagger,}$ A. Giugni, ${ }^{\dagger}$ G. Moroso, ${ }^{\dagger}$ and A. Vaccari ${ }^{*}{ }^{\ddagger}$ \\ ${ }^{\dagger}$ Dipartimento di Scienza e Alta Tecnologia, Università degli Studi dell'Insubria, via Valleggio 11, 22100 Como, Italy

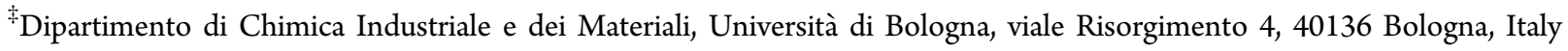

ABSTRACT: The nature of the interaction on two different catalysts (zeolite BEA and $\gamma$-alumina) of some aromatic substrates, 1,2-methylendioxybenzene, 1,2-ethylendioxybenzene, and 1,2-dimethoxybenzene, have been investigated by FT-IR spectroscopy. FT-IR data suggest that the adsorption of 1,2-methylendioxybenzene occurs through oxygen atoms and the molecule maintains the original puckered conformation, whereas the planar structure due to the absence of a fused ring in the case of 1,2dimethoxybenzene and the twisted conformation of 1,2-ethylendioxybenzene cause an orientation of the molecules parallel to the catalyst surface, with the benzene ring directly interacting to it. The puckered conformation of MDB leads the benzene ring to

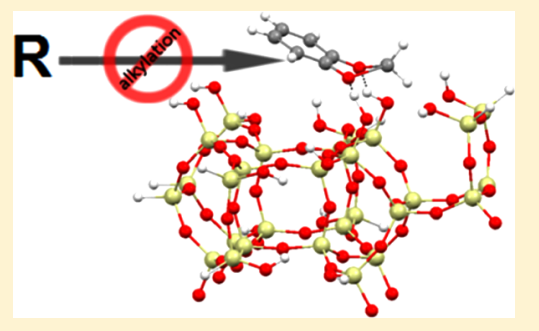
be electron-deficient, then deactivated toward alkylation, such as confirmed by the obtained catalytic results, which show that $\mathrm{MDB}$ is totally not reactive using the investigated heterogeneous catalysts, while in the traditional homogeneous system shows a reactivity comparable to the other considered substrates.

\section{INTRODUCTION}

Alkylation of aromatic hydrocarbons is one of the most useful reactions in organic chemistry for the synthesis of petrochemicals, intermediates, and fine chemical products. ${ }^{1}$ The high costs in terms of product purification and toxic waste disposal make it imperative for research to develop new processes based on solid catalysts. Petrochemical traditional reactions have been replaced with new ones based on solid-acid catalysts: ${ }^{2,3}$ benzene, toluene, biphenyl, and naphthalene alkylations ${ }^{4-10}$ may be cited as examples. In the field of fine chemicals, most of the current processes are still based on homogeneous catalysts. $^{2,11}$ 5-Substituted benzo[1,3] dioxole derivatives are important compounds in the manufacture of fragrances (Piperonal, Helional), drugs (Tadafil, Anolignan A, etc.), and agrochemicals (Piperonyl Butoxide). ${ }^{12-15}$

In this work, the attention was first focused on Helional (3[3,4-methylendioxyphenyl]-2-methyl-propionaldehyde), whose synthesis starting from 1,2-methylenedioxybenzene (MDB) is industrially carried out in the liquid phase, using Lewis acid catalysts and operating in batch conditions. The reactivity of MDB with solid catalysts has not been as thoroughly studied as that of benzene or toluene; ${ }^{3-6}$ the only example of heterogeneous reaction is the acetylation reported by Spagnol et al. ${ }^{16}$ in the presence of beta zeolite carried out batchwise with a $61 \%$ yield.

In the literature, many processes are reported for the alkylation of aromatic substrates with alkenylidenediacetate; these are carried out in the liquid phase by using homogeneous catalytic systems such as $\mathrm{TiCl}_{4}$ and $\mathrm{AlCl}_{3}$, metal halides, or boron trifluoride-diethylether complexes. These processes could be used for the synthesis of 1-acetoxy-2-methyl-3-(3,4methylendioxyphenyl)propene (precursor of Helional). ${ }^{17-20}$ Several authors have suggested some alternative routes for the synthesis of 5-alkylbenzo[1,3] dioxole avoiding the alkylation of MDB. In particular, Borzatta et al. ${ }^{21,22}$ described two multistep processes starting from the acylation of MDB or from 4acylphenol, while Zelle et al. ${ }^{23}$ described one process starting from the reaction of 4-alkyl-catechols with methylene dihalide. A review of the literature ${ }^{3,4,6,7,11}$ shows that catalytic alkylations of aromatic hydrocarbons are important reactions and have been studied in depth in recent years, with the most studied reactions being the alkylation of benzene and alkyl-substituted benzene.

Conversely, for oxygen-containing benzene derivatives no data on the reactivity with heterogeneous catalytic systems are available, thus suggesting that in this case the reaction is much more demanding. A detailed look at the step by-step process through which the reaction occurs may be an interesting way to verify the effective feasibility of the alkylation. Spectroscopic techniques have been used to study the alkylation of benzene or alkylbenzene derivatives with alkylating agents (methanol, ethylene, propylene, 2-propanol, etc.) on solid-acid catalyst such as zeolite. The nature of the acid sites of zeolite is unanimously recognized. ${ }^{24-26}$ A number of papers have been published on the interaction between aromatic substrates and the catalyst surface, but some debate still exists. The interaction of different classes of aromatic hydrocarbons, such as benzene and toluene, with the protonic sites of zeolites has been studied using IR spectroscopy. In the above-mentioned papers the attention has mainly been focused on the interaction between the molecule and the acid sites, leading to the evaluation of their nature and location, without considering the evolution of

Received: March 9, 2012

Revised: September 18, 2012

Published: September 19, 2012 
the properties of aromatic ring. ${ }^{27-32}$ Nevertheless, the activation and reactivity of different alkylating agents such as methyl, propyl, etc. on zeolite catalysts are well-known today. ${ }^{33-39}$

The aim of this work is to clarify catalytic behavior of complex aromatic substrates using FT-IR spectroscopy. The experimental FT-IR spectra were complemented with ab initio calculations of the IR frequencies to help the assignment of the bands.

\section{EXPERIMENTAL SECTION}

1,2-Methylendioxybenzene (MDB) (99\%), 1,2-ethylendioxybenzene (EDB) (97\% wt \%), 1,2-dimethoxybenzene (DEB) (99\% wt \%), acrolein diethyl acetal (AEA) (96\% wt \%), 2propanol (99.5\%), 1-bromopropane (99\%), sulfuric acid (96\%), anhydrous aluminum chloride $(\geq 99.9 \%)$, anhydrous sodium sulfate $(\geq 99.0 \%)$, and dichloromethane $(\geq 99.9 \%)$ were purchased from Aldrich Chemicals and used without any further purification. Different commercial solid-acid catalysts have been studied such as $\gamma-\mathrm{Al}_{2} \mathrm{O}_{3}$ (Sasol), acid-treated clay (Engelhard, F-13), and a beta zeolite (Zeocat PB). Before the tests all of the samples were calcined at $500{ }^{\circ} \mathrm{C}$ for $6 \mathrm{~h}$. The heterogeneous gas phase catalytic tests were carried out at atmospheric pressure in a fixed bed continuous-flow reactor (length $390 \mathrm{~mm}$ and inner diameter $8 \mathrm{~mm}$ ) at $300{ }^{\circ} \mathrm{C}$ using $\mathrm{N}_{2}$ as the carrier gas. The reactor was charged with $1 \mathrm{~cm}^{3}$ (particle size 40-60 mesh) of fresh catalyst. Aromatic substrates (MDB, $\mathrm{EDB}$, and $\mathrm{DEB}$ ) were fed in excess to the alkylating agents (acrolein diethyl acetal or 2-propanol) in a molar ratio of 3 . The reaction mixture was fed using a syringe pump and vaporized into a preheated flow of $\mathrm{N}_{2}$, set to reach a 9:1 volume ratio of $\mathrm{N}_{2}$ to organic mixture (aromatic substrate and alkylating agent). All runs were performed at a contact time of 1s. During the catalytic tests the outlet stream was condensed in HPLC-grade acetone, and cooled in an ice bath at $0{ }^{\circ} \mathrm{C}$ for $1 \mathrm{~h}$. Blank tests, without a catalyst, at the same reaction temperature did not show any reaction and/or decomposition.

Liquid phase heterogeneously catalyzed tests were conducted in a glass batch reactor equipped with reflux condenser, by reacting $2.5 \mathrm{mmol}$ of aromatic substrate in $5 \mathrm{~mL}$ of 2-propanol with $0.1 \mathrm{mg}$ of catalyst at boiling temperature of the alchool for $2 \mathrm{~h}$. The obtained mixture was filtered before to be analyzed.

Two different procedures were employed in the homogeneous tests: (1) $49.0 \mathrm{mmol}$ of aromatic substrate were added to $3.0 \mathrm{mmol}$ of anhydrous aluminum chloride. Then $49.0 \mathrm{mmol}$ of 1-bromopropane were added dropwise, keeping the mixture under stirring for $30 \mathrm{~min}$ at $40^{\circ} \mathrm{C}$. A total of $5 \mathrm{~mL}$ of cold water were added to the solution then organic phase was diluted with $\mathrm{CH}_{2} \mathrm{Cl}_{2}$ and dried with anhydrous sodium sulfate before analysis. (2) $2.2 \mathrm{mmol}$ of aromatic substrate were mixed with $0.5 \mathrm{~mL}$ of 2-propanol then $1 \mathrm{~mL}$ of sulfuric acid was added dropwise keeping the solution into an ice bath. Afterward, the mixture was allowed to warm at room temperature and the reaction was pursued for further $10 \mathrm{~min}$. Then, a procedure similar to that previously described for $\mathrm{AlCl}_{3}$ was followed before the analysis.

All of the obtained solutions were analyzed using a Carlo Erba 4300 gas chromatograph, equipped with FID and a widebore OV1 column (length $30 \mathrm{~m}$, i.d. $0.53 \mathrm{~mm}$, film width 0.5 $\mu \mathrm{m})$ and identified by GC-MS analysis using an Agilent Technology $6890 \mathrm{~N}$ equipped with a 5973 mass selective detector and an HP5 column (length $25 \mathrm{~m}$, i.d. $0.25 \mathrm{~mm}$, film width $1.5 \mu \mathrm{m}$ ).

The IR spectra after adsorption of reactants were recorded using a Perkin-Elmer Spectrum One spectrometer. Zeolite and alumina samples were pressed into self-supported wafer and activated in situ in the IR cell at $500^{\circ} \mathrm{C}$ under a vacuum $\left(\leq 10^{-7}\right.$ mbar) for $1 \mathrm{~h}$. Before measuring the IR spectra, the activated sample was contacted with an increasing amount of the adsorbent at room temperature. Desorption spectra were recorded at temperature increasing from room to $500{ }^{\circ} \mathrm{C}$. For recording spectra, 12 scans were coadded with a resolution of $1 \mathrm{~cm}^{-1}$ in the region of $4000-450 \mathrm{~cm}^{-1}$.

IR frequencies of $\mathrm{MDB}, \mathrm{EDB}$, and $\mathrm{DEB}$ molecules were calculated at the MP2(FC) level using the $6311 \mathrm{G}(\mathrm{d}, \mathrm{p})$ basis set by the Gaussian 09 software package. ${ }^{40}$ IR frequencies were scaled by a factor of $0.9496 .^{41}$

\section{RESULTS AND DISCUSSION}

The alkylation of MDB with 3-diacetoxy-2-methylpropene gives 1-acetoxy-2-methyl-3-(3,4-methylendioxyphenyl) propene (precursor of Helional), which can be easily hydrolyzed to the desired aldehyde, Helional. In the present work gas phase alkylation of MDB was studied using acrolein diethyl acetal (AEA) as a commercially available model of 3-diacetoxy-2methylpropene (Scheme 1).

\section{Scheme 1. Alkylation of MDB with AEA}

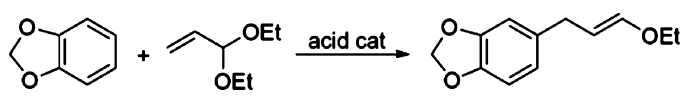

Catalytic Tests. Three solid catalysts with different acidbase properties were tested at $300{ }^{\circ} \mathrm{C}: \gamma-\mathrm{Al}_{2} \mathrm{O}_{3}$, acid-treated clay (Engelhard F-13), and beta zeolite (Zeocat PB; Table 1).

Table 1. Acidity and Activity of the Tested Samples at $300^{\circ} \mathrm{C}$

$\begin{array}{ccccc}\text { catalyst } & \begin{array}{c}\text { acid amount } \\ \left(\mathrm{mmol} \mathrm{NH} \mathrm{g}_{\text {cat }}\right)\end{array} & \begin{array}{c}\mathrm{AEA} \text { conv } \\ (\%)\end{array} & \begin{array}{c}\text { MDB conv } \\ (\%)\end{array} & \begin{array}{c}\text { yield } \\ (\%)\end{array} \\ \gamma-\mathrm{Al}_{2} \mathrm{O}_{3} & 0.05 & 35 & 10 & 0 \\ \mathrm{~F}-13 & 0.4 & 85 & 14 & 0 \\ \mathrm{Zeocat} & 0.5 & 90 & 9 & 0 \\ \mathrm{~PB} & & & & \end{array}$

GC-MS analysis of the condensed outlet stream does not show the formation of products. The conversion of AEA is mostly due to its decomposition (to acetaldehyde, ethanol, propanal, 1-propene-3-ethoxy, and ethyl-1-propenyl ether) and heavy byproducts formation. MDB is involved only in undesired reactions yielding heavy byproducts, which remain adsorbed on the catalyst surface.

These results may be explained by two phenomena: (i) AEA totally decomposes before reacting with the aromatic substrate and (ii) $\mathrm{MDB}$ is not reactive in the tested conditions. In order to verify the first hypothesis, AEA reactivity was studied in the $140-350{ }^{\circ} \mathrm{C}$ range, feeding $0.75 \mathrm{~mL} / \mathrm{h}$ of AEA in a preheated flow $(20 \mathrm{~mL} / \mathrm{min})$ of $\mathrm{N}_{2}$ on a beta zeolite sample. The results show that the compound decomposes from about 20 to $100 \%$ throughout the whole temperature range investigated. In particular when operating at $300{ }^{\circ} \mathrm{C}$ the reactant totally decomposes within the first hour, and the decomposition decreases with time on stream due to catalyst deactivation by coke formation. Thus, at operating conditions, this molecule is 
not stable enough to alkylate an aromatic substrate. Thus the alkylation of MDB was then studied using 2-propanol, a more stable alkylating agent, whose activity has been studied in depth in gas phase aromatic alkylation. ${ }^{5,6,42}$ For the sake of comparison the same reaction was carried out on ethylendioxy and dimethoxy-substituted benzene derivatives, 1,2-ethylendioxybenzene (EDB) and 1,2-dimethoxybenzene (DEB). Tests were conducted over zeolite BEA, $\gamma$-alumina, and acid treated clay samples. MDB shows a conversion lower than $10 \%$ and no evidence of products formation over all of the catalysts investigated, whereas EDB readily reacts (conversion from $60 \%$ to $70 \%$ ) with 2-propanol to give monoalkylated products which undergo further polyalkylation to di- and tri-isopropyl-EDB; the products distribution depends on the acidity of the tested catalyst. Finally, in the case of DEB the reaction (conversion $\sim 90 \%$ for all of the catalysts) leads to the formation of monoand dialkylated derivatives which undergo Fries rearrangement ${ }^{43}$ to yield a very complex products mixture.

In order to understand if the above-reported results are due to the heterogeneity of the catalytic system or to operating conditions (gas or liquid phase) similar tests were performed in liquid phase, both in heterogeneous (alumina and zeolite) and homogeneous systems $\left(\mathrm{AlCl}_{3}\right.$ and $\left.\mathrm{H}_{2} \mathrm{SO}_{4}\right)$. In the former case, MDB is totally unreactive, whereas EDB reaches conversions of $43 \%$ and $29 \%$ using zeolite and alumina, respectively; DEB shows higher conversion ( 52 and $38 \%$ ) with the formation of mono- and dialkylated products.

The tests performed using homogeneous catalysts show different results: as expected, EDB and DEB are highly reactive, reaching conversion values between 70 and $80 \%$, with good selectivity values in monoalkylated products. MDB shows a completely different reactivity compared to the tests with the heterogeneous catalysts. In fact for both homogeneous investigated catalysts, a conversion of about $40 \%$ is obtained, with formation of mono- and dialkylated products.

Summarizing, the three considered molecules show a good reactivity in well-known homogeneous conditions, while only MDB is totally unreactive on solid acidic catalysts. Then the different behaviors in heterogeneous catalysis between the substrates studied may be caused by the geometric conformation of the molecules, which causes a different interaction of the benzene moiety with the catalyst surface. In order to verify this hypothesis the conformational properties of MDB, $\mathrm{EDB}$ and $\mathrm{DEB}$ were studied and geometry optimizations were carried out.

Molecular Structure. The results indicate that the two disubstituted species with fused ring show different lowestenergy forms, twisted in the case of EDB (Figure 1a) and puckered for MDB (Figure 1b). When considering the

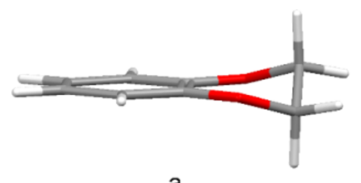

a

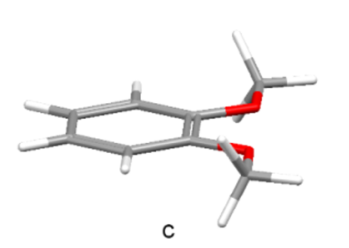

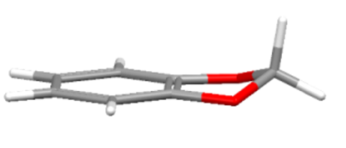

b
Figure 1. Lowest energy forms for (a) EBD, (b) MDB, and (c) DEB. molecule with free substituents DEB, according to the calculations of Dorofeeva et al., ${ }^{44}$ it has three stable conformers: anti-anti with a plane backbone, anti-gauche with one orthogonal, and gauche-gauche with two orthogonal methyl groups. The absolute minimum corresponds to the anti-anti conformer (Figure 1c), but it is lower than the anti-gauche by less than $1 \mathrm{kcal} / \mathrm{mol}$, whereas the gauche-gauche is much higher in energy. However, only the planar structure was used for IR assignment and frequencies are reported only for this conformer.

These results strongly support the idea that the three molecules should yield different energetically most favored adsorption configurations on the catalyst surface, resulting in a different activation of the benzene ring. Vibrational spectroscopic techniques should be suitable for studying the interaction of the molecules with the catalytic sites. In order to explain the reactivity differences observed in the catalytic tests a FT-IR study of the adsorption of each of the substrates on beta zeolite has been carried out and a comparative analysis using MDB and EDB was performed on gamma alumina, to be sure that the results are not due to the specific texture of the materials.

Vibrational Assignements. The tables below summarized the vibrational frequencies, experimental and calculated, of free pure molecules. Moreover in the same tables are listed the frequencies related to the adsorption (I, II) on zeolite at increasing amounts of aromatic substrates and those related to the desorption step at increasing temperature (room temperature and 100,200 , and $500{ }^{\circ} \mathrm{C}$ ), for the sake of concision frequencies for IR spectra on alumina are not listed.

Vibrational assignements of experimental infrared spectra have been made by comparing them with those previously reported in the literature $e^{45-48}$ and with the computed ones. The frequencies and the intensities of the experimental infrared spectra of the three molecules are quite nicely predicted by the calculation, and almost all the computed frequencies are easily assigned to observed bands even if in some cases this requires several reassignements compared the literature. ${ }^{45-48}$

H-Beta Zeolite and Gamma Alumina FT-IR Characterization. The spectrum of calcined zeolite after evacuation at $500{ }^{\circ} \mathrm{C}$ shows four signals at $3779,3742,3660$, and $3604 \mathrm{~cm}^{-1}$ (Figure 2, solid line). The two main peaks at 3742 and 3604

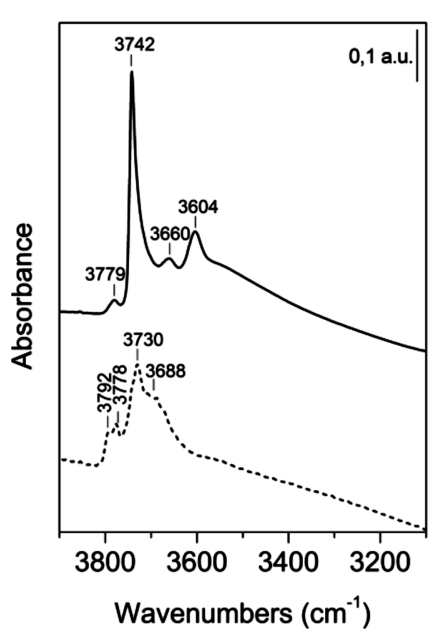

Figure 2. $\mathrm{OH}$ spectral pattern of $\mathrm{H}-\mathrm{BEA}$ (solid spectrum) and $\gamma-\mathrm{Al}_{2} \mathrm{O}_{3}$ (dashed spectrum) samples after evacuation at $500{ }^{\circ} \mathrm{C}$ for $6 \mathrm{~h}$. 
$\mathrm{cm}^{-1}$ correspond to terminal silanols and bridging framework $\mathrm{Si}-\mathrm{OH}-\mathrm{Al}$ groups, respectively. The other two small peaks at 3779 and $3660 \mathrm{~cm}^{-1}$ have been attributed respectively both to the $\mathrm{Al}-\mathrm{OH}$ species, being near to $\mathrm{Si}-\mathrm{OH}$ groups generated when $\mathrm{Al}$ leaves the framework, and to the hydroxyls associated with extra-framework aluminum. ${ }^{24-26}$ The four $\mathrm{OH}$ peaks are superimposed on a broad band at $3700-3200 \mathrm{~cm}^{-1}$ due to the hydrogen-bonded bridging $\mathrm{OH}$ groups. ${ }^{25}$

The alumina spectrum after evacuation at $500{ }^{\circ} \mathrm{C}$ (Figure 2, dashed line) shows the typical signals attributed to the different types of hydroxyl groups. In particular the main bands at 3792/ 3778,3730 , and $3688 \mathrm{~cm}^{-1}$ may be attributed to isolated hydroxyl groups of I, II, and III types, whereas the broad band centered around $3580 \mathrm{~cm}^{-1}$ is due to the H-bonded hydroxyl groups. $^{49-53}$

Interaction of MDB with the Catalysts. The formation of a hydrogen-bonded adduct is evident after adsorption of MDB, as confirmed by the strong spectral perturbations shown in Figure 3, whereas all vibrational assignments are summarized in

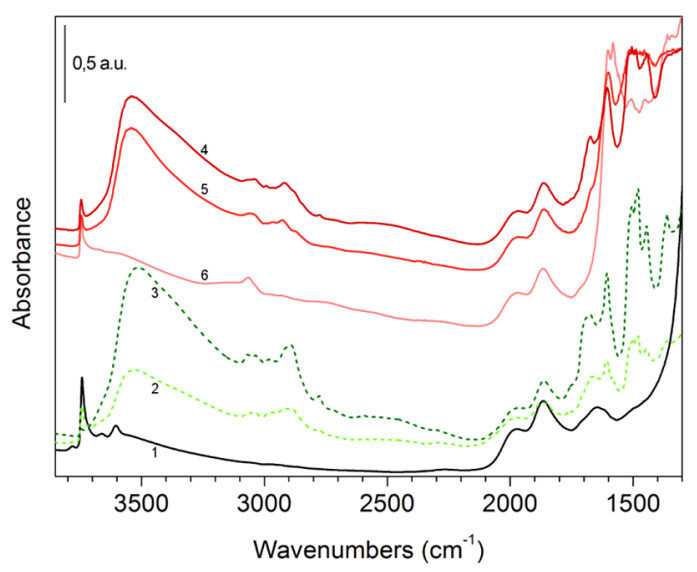

Figure 3. FTIR spectra of increasing dosages of MDB on H-BEA followed by evacuation at increasing temperatures. (1) Solid black spectrum, H-BEA calcined at $500{ }^{\circ} \mathrm{C}$ for $6 \mathrm{~h}$; dashed green scale spectra, adsorption of MDB at RT (2) medium and (3) high coverages; solid red scale spectra, desorption steps at increasing temperatures (4) 100, (5) 200, and (6) $500{ }^{\circ} \mathrm{C}$.

Table 2. On increasing the dosage of MDB, the band at 3742 $\mathrm{cm}^{-1}$ is strongly eroded and the other hydroxyl bands (3779, 3660 , and $3604 \mathrm{~cm}^{-1}$ ) disappear completely. Simultaneously, an intense band centered at $3530 \mathrm{~cm}^{-1}$ grows and shifts toward lower wavenumbers $\left(3513 \mathrm{~cm}^{-1}\right)$ with increasing $\mathrm{MDB}$ coverage, as shown in Figure 3.

The present results show that all hydroxyl groups are strongly affected by the adsorption of MDB; this strong interaction is confirmed by the presence of a very intense and irreversible $27,54,55$ adsorption (the zeolite feature is not totally restored after outgassing at $500{ }^{\circ} \mathrm{C}$ ) due to the formation of an $\mathrm{H}$-bonded complex. Considering the strength of the linkage, it is possible to hypothesize the formation of a strong H-bond between the zeolite and the organic substrate (zeolite $\mathrm{O}-$ $\left.\mathrm{H} \bullet \bullet \bullet \mathrm{O}_{M D B}\right)$ due to a preferential adsorption through oxygen atoms. ${ }^{26,56-59}$ The changes in relative intensity of some band after heating at high temperature may be ascribed to the partial decomposition of the molecule. Two broad bands near 3090 and $2450 \mathrm{~cm}^{-1}$ with a window in the middle, near $2700 \mathrm{~cm}^{-1}$, may be associated with Fermi resonance produced by interactions of the acidic zeolite $\mathrm{OHs}$ with a base, in this case MDB (Figure 3). ${ }^{26,54,57,60}$

It is difficult to interpret the spectra in the (aliphatic and aromatic) $\mathrm{C}-\mathrm{H}$ stretching region, shown in Figure 4, as the differences in the vibrational properties, caused by interaction with the zeolite, are rather complex. With regard to the aromatic ring the most evident spectral perturbation is the shift of the band at $3050 \mathrm{~cm}^{-1}$ toward lower wavenumbers, probably due to the strong $\mathrm{H}$-bond between oxygen and silanols that perturbs the electronic cloud of the aromatic ring. The appearance, in the $\mathrm{CH}_{2}$ stretching region, of a new band at $2916 \mathrm{~cm}^{-1}$ may be ascribed to the interaction between the hydrogens of the methylene group and the oxygen of the zeolite lattice. Consequently, the $\mathrm{CH}_{2}$ deformation at 1501 $\mathrm{cm}^{-1}$ is also perturbed, resulting in a shift toward higher wavenumbers (Figure 5). Focusing the attention on the spectral region between 1800 and $1000 \mathrm{~cm}^{-1}$ (Figure 5), it is possible to see that the bands due to $\mathrm{C}-\mathrm{C}$ ring vibrations are almost unaffected by adsorption, thus indicating that there is no direct interaction of the aromatic ring with the catalyst. The vibrational modes of $\mathrm{C}-\mathrm{O}$ are strongly perturbed, in particular the $\mathrm{C}-\mathrm{C}-\mathrm{O}$ symmetric and asymmetric stretching at 1479 and $1447 \mathrm{~cm}^{-1}$ are shifted toward lower wavenumbers, whereas the $\mathrm{C}-\mathrm{C}-\mathrm{O}$ symmetric stretching at $1232 \mathrm{~cm}^{-1}$ and $\mathrm{O}-\mathrm{C}-\mathrm{O}$ asymmetric stretching at $1041 \mathrm{~cm}^{-1}$ are shifted toward higher wavenumbers. These latter results confirm that interaction occurs preferentially through oxygen atoms; the MDB maintains the puckered conformation after adsorption, resulting in an electronic deactivation of benzene ring. ${ }^{61}$

A similar behavior has been observed in the case of alumina (Figure 6). Adsorption of MDB strongly perturbs the hydroxyl groups of alumina, resulting in the growth of the strong band centered around $3540 \mathrm{~cm}^{-1}$. Changes observed in $\mathrm{C}-\mathrm{C}$ and $\mathrm{C}-\mathrm{H}$ stretching vibrations follow the same behavior which has been already observed for zeolite. As in the case of zeolite a negligible shift of the $\mathrm{C}-\mathrm{C}$ and $\mathrm{C}-\mathrm{H}$ stretching of benzene ring is observed, whereas strong changes in $\mathrm{C}-\mathrm{O}$ and $\mathrm{CH}_{2}$ vibrational modes occur. In particular, aliphatic $\mathrm{C}-\mathrm{H}$ stretching at $2891 \mathrm{~cm}^{-1}$ shifts to lower wavenumbers, whereas the bands attributed to $\mathrm{C}-\mathrm{C}-\mathrm{O}$ vibrations $\left(1479,1447\right.$, and $\left.1232 \mathrm{~cm}^{-1}\right)$ and the one associated to symmetric $\mathrm{O}-\mathrm{C}-\mathrm{O}$ stretching at $1041 \mathrm{~cm}^{-1}$ are shifted to higer wavenubers. News bands at 1598 and $1497 \mathrm{~cm}^{-1}$ and in the region between 1330 and $1220 \mathrm{~cm}^{-1}$, still detectable after evacuation at $500{ }^{\circ} \mathrm{C}$, may be assigned to the formation of phenate species due to the partial decomposition of MDB. ${ }^{62}$

Interaction of EDB with the Catalysts. A detailed analysis of FT-IR spectra of adsorbed EDB on zeolite sample is reported below, whereas the vibrational frequencies are reported in Table 3. As shown in Figure 7, upon increasing the EDB load the silanol band at $3783 \mathrm{~cm}^{-1}$ gradually disappears, with a parallel growth of a small adsorption at $3686 \mathrm{~cm}^{-1}$, which may be attributed to the interaction of the aromatic ring with silanol groups. ${ }^{24,25}$ The remaining silanol bands (3746, 3667 , and $3610 \mathrm{~cm}^{-1}$ ) are almost unaffected, whereas the broad band at $3700-3200 \mathrm{~cm}^{-1}$ results in an increase in intensity and in a shift toward lower wavenumbers. A shoulder at about 3250 $\mathrm{cm}^{-1}$ may be attributed to the H-bonding complex of the benzene ring and bridging $\mathrm{OHs}$ according to Trombetta et al. ${ }^{32}$ Upon formation of a weak hydrogen bond, in Figure 7 it is possible to distinguish two broad bands in the region of 2970 and $2420 \mathrm{~cm}^{-1}$ with a window at around $2600 \mathrm{~cm}^{-1}$ attributable to the $\mathrm{A}$ and $\mathrm{B}$ components of Fermi resonance. ${ }^{26,54,57,60}$ 
Table 2. Vibrational Assignments $\left(\mathrm{cm}^{-1}\right)$ for $\mathrm{MDB}^{a}$

\begin{tabular}{|c|c|c|c|c|c|c|c|c|}
\hline & \multirow[b]{3}{*}{ description } & \multicolumn{7}{|c|}{ wavenumbers $\left(\mathrm{cm}^{-1}\right)$} \\
\hline & & \multirow[b]{2}{*}{ pure calculated $^{b}$} & \multirow[b]{2}{*}{ pure } & \multicolumn{2}{|c|}{ adsorptions } & \multicolumn{3}{|c|}{ desorptions } \\
\hline & & & & I & II & $100{ }^{\circ} \mathrm{C}$ & $200{ }^{\circ} \mathrm{C}$ & $500{ }^{\circ} \mathrm{C}$ \\
\hline \multirow[t]{4}{*}{ zeolite } & $\nu \mathrm{Al}-\mathrm{OH}$ near $\mathrm{SiOH}$ & & 3779 & & & & & \\
\hline & $\nu \mathrm{Si}-\mathrm{OH}$ terminal & & 3742 & 3743 & 3742 & 3745 & 3744 & 3745 \\
\hline & $\nu \mathrm{Al}-\mathrm{OH}$ extra-framework $\mathrm{Al}$ & & 3660 & & & & & \\
\hline & $\nu \mathrm{Si}-\mathrm{OH}-\mathrm{Al}$ bridging framework & & 3604 & & & & & \\
\hline \multirow[t]{19}{*}{ MDB } & H-bondend complex & & & 3530 & 3511 & 3542 & 3543 & \\
\hline & $\nu$ sym ip $\mathrm{C}-\mathrm{H}$ & 3082 & 3097 & 3097 & 3097 & & & \\
\hline & $\nu$ asym ip $\mathrm{C}-\mathrm{H}$ & 3078 & 3066 & 3068 & 3068 & 3068 & 3065 & 3064 \\
\hline & $\nu$ sym op $\mathrm{C}-\mathrm{H}$ & 3066 & 3050 & 3036 & 3035 & 3035 & & \\
\hline & $\nu$ asym op $\mathrm{C}-\mathrm{H}$ & 3053 & 3011 & & & & & \\
\hline & $\nu$ asym op $\mathrm{CH}_{2}$ & 3046 & 2981 & 2982 & 2992 & 2992 & & \\
\hline & $\nu \mathrm{CH}_{2}(\mathrm{CH} \cdots \mathrm{OSi})$ & & & 2916 & 2916 & 2919 & 2926 & \\
\hline & $\nu$ sym $\mathrm{C}-\mathrm{H}\left(\mathrm{CH}_{2}\right)$ & 2896 & 2891 & 2891 & 2891 & & & \\
\hline & $\nu \mathrm{C}-\mathrm{C}$ benzene & 1589 & 1628 & & & & & \\
\hline & $\nu \mathrm{C}-\mathrm{C}$ benzene & 1577 & 1604 & 1606 & 1606 & 1605 & 1600 & 1602 \\
\hline & $\delta_{\mathrm{s}} \mathrm{CH}_{2}$ & 1487 & 1501 & 1502 & 1502 & 1504 & & \\
\hline & $\nu \mathrm{C}-\mathrm{C}$ benzene $+\nu$ sym $\mathrm{CCO}$ & 1445 & 1479 & 1479 & 1479 & & & \\
\hline & $\nu \mathrm{C}-\mathrm{C}$ benzene $+\nu$ asym $\mathrm{CCO}$ & 1420 & 1447 & 1444 & 1445 & 1445 & & \\
\hline & $\nu \mathrm{C}-\mathrm{C}$ benzene & 1398 & 1361 & 1361 & 1361 & & & \\
\hline & $\nu$ sym $\mathrm{C}-\mathrm{C}-\mathrm{O}$ & 1237 & 1232 & 1237 & 1237 & & & \\
\hline & $\omega$ op, op' $\mathrm{C}-\mathrm{H}$ & 1114 & 1152 & & & & & \\
\hline & $\nu \mathrm{C}-\mathrm{C}$ benzene $+\nu$ asym $\mathrm{CO}$ & 1112 & 1125 & & & & & \\
\hline & $\nu \mathrm{C}-\mathrm{C}$ benzene $+\nu$ asym $\mathrm{CO}$ & 1054 & 1092 & & & & & \\
\hline & $\nu$ sym $\mathrm{O}-\mathrm{C}-\mathrm{O}$ & 1027 & 1041 & 1051 & & & & \\
\hline
\end{tabular}

${ }^{a}$ Abbreviations: $\nu$, stretching; $\omega$, wagging; $\tau$, twisting; $\delta$ s, scissoring; $\rho$, rockin; ip, in phase; op, out of phase. ${ }^{b}$ Calculated at MP2(FC) level using the $6311 \mathrm{G}(\mathrm{d}, \mathrm{p})$ basis set by the Gaussian 09 software package. ${ }^{40}$ IR frequencies were scaled by a factor of $0.9496 .{ }^{41}{ }^{c}$ Pure gas phase molecule.

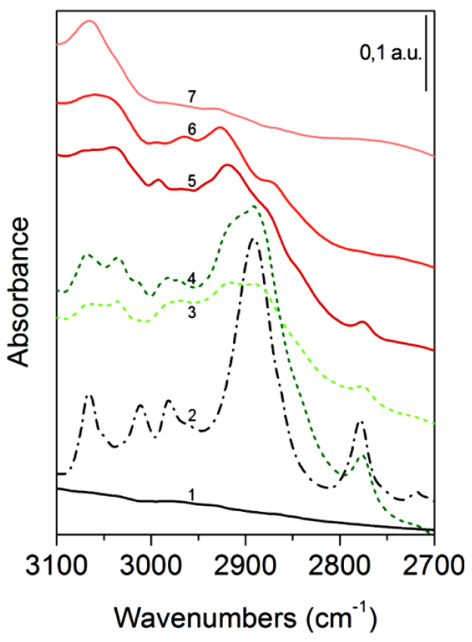

Figure 4. FTIR spectra, in the $\mathrm{C}-\mathrm{H}$ stretching region, of increasing dosages of $\mathrm{MDB}$ on $\mathrm{H}-\mathrm{BEA}$ followed by evacuation at increasing temperatures. (1) Solid black spectrum, H-BEA calcined at $500{ }^{\circ} \mathrm{C}$ for $6 \mathrm{~h}$; (2) dashed-dotted black spectrum, pure MDB; dashed green scale spectra, adsorption of MDB at RT (3) medium and (4) high coverages; solid red scale spectra, desorption steps at increasing temperatures (5) 100, (6) 200, and (7) $500{ }^{\circ} \mathrm{C}$.

On the basis of these results, it is possible to hypothesize the planar adsorption of EDB on the catalyst surface, considering that (i) there is no evidence of interaction between the oxygen atoms of EDB and silanols and (ii) the perturbation of $\mathrm{H}$ bonded hydroxyls is caused by delocalized $\pi$-type orbitals of aromatics. ${ }^{30}$ The interaction is completely reversible and by far weaker than that observed in the case of MDB, as confirmed by

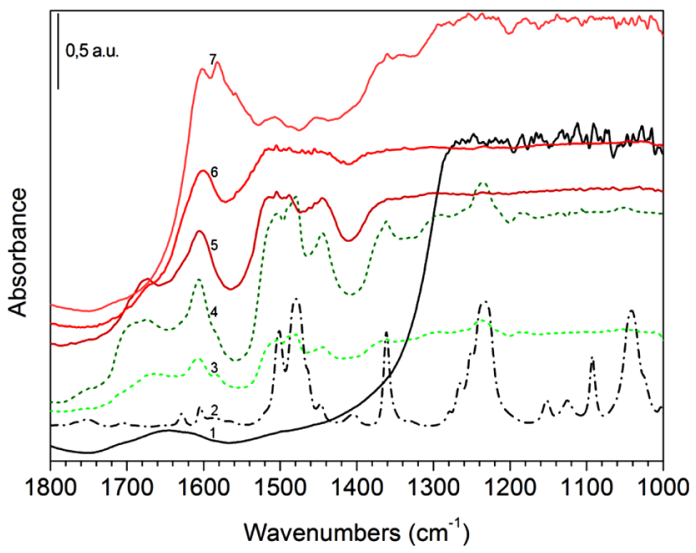

Figure 5. FTIR spectra, in the region $1800-1000 \mathrm{~cm}^{-1}$, of increasing dosages of MDB on H-BEA followed by evacuation at increasing temperatures. (1) Solid black spectrum, H-BEA calcined at $500{ }^{\circ} \mathrm{C}$ for $6 \mathrm{~h}$; (2) dashed-dotted black spectrum, pure MDB; dashed green scale spectra, adsorption of MDB at RT (3) medium and (4) high coverages; solid red scale spectra, desorption steps at increasing temperature (5) 100, (6) 200, and (7) $500{ }^{\circ} \mathrm{C}$.

the total restoration of the original spectrum when the temperature reaches at $200{ }^{\circ} \mathrm{C}$. Our previous hypothesis is supported by the shift upward of all the aromatic $\mathrm{CH}$ and aliphatic $\mathrm{CH}_{2}$ stretching vibrations, a shift which increases with temperature, thus indicating the formation of stronger bonded species (see Figure 8).

Moreover, analyzing the region between 1800 and $1300 \mathrm{~cm}^{-1}$ (Figure 9), the shift upward of $\mathrm{C}-\mathrm{C}$ stretching vibrations is a further evidence that EDB adsorption occurs through the 


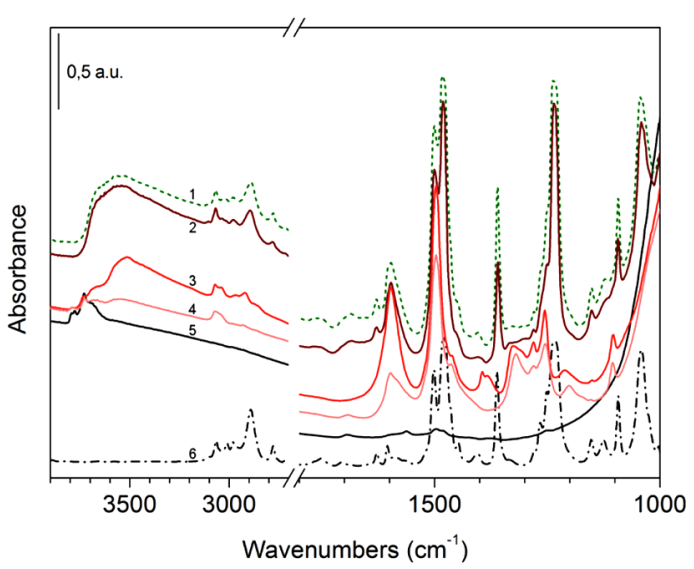

Figure 6. Changes in FTIR spectra of $\gamma-\mathrm{Al}_{2} \mathrm{O}_{3}$ produced by adsorption of MDB followed by desorption at increasing temperatures. (1) Green dashed spectrum, adsorbed MDB; solid red scale spectra, desorption steps at increasing temperatures (2) RT, (3) $200{ }^{\circ} \mathrm{C}$ and (4) $500{ }^{\circ} \mathrm{C}$;

(5) solid black spectrum, $\gamma-\mathrm{Al}_{2} \mathrm{O}_{3}$ after evacuation at $500{ }^{\circ} \mathrm{C}$ for $6 \mathrm{~h}$;

(6) dashed-dotted black black spectrum, pure MDB.

benzene ring, then the interaction involves $\mathrm{C}=\mathrm{C} \pi$-type orbitals, as reported by Trombetta et al. ${ }^{30,32}$ In the same region an intense band at $1693 \mathrm{~cm}^{-1}$, with a shoulder at $1708 \mathrm{~cm}^{-1}$, and two bands at 1419 and $1370 \mathrm{~cm}^{-1}$ appear. These three

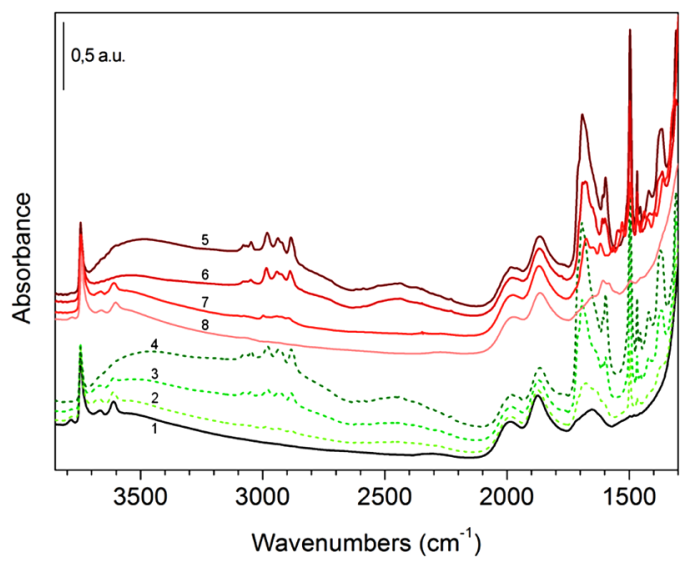

Figure 7. FTIR spectra of increasing dosages of EDB on H-BEA followed by evacuation at increasing temperatures. (1) Solid black spectrum, H-BEA calcined at $500{ }^{\circ} \mathrm{C}$ for $6 \mathrm{~h}$; dashed green scale spectra, adsorption of EDB at RT (2) low, (3) medium, and (4) high coverages; solid red scale spectra, desorption steps at increasing temperatures (5) RT, (6) $100{ }^{\circ} \mathrm{C}$, (7) $200{ }^{\circ} \mathrm{C}$, and (8) $500{ }^{\circ} \mathrm{C}$.

latter bands are due to the formation of a bicoordinated adduct in which one of the two methylene carbons interacts with two adjacent oxygens of the zeolite lattice. This interaction may be ascribed to the complex formed by $\mathrm{CO}_{2}$ with zeolite oxygen,

Table 3. Vibrational Assignments $\left(\mathrm{cm}^{-1}\right)$ for $\mathrm{EDB}^{a}$

\begin{tabular}{|c|c|c|c|c|c|c|c|c|c|c|}
\hline & \multirow[b]{3}{*}{ description } & \multicolumn{9}{|c|}{ wavenumbers $\left(\mathrm{cm}^{-1}\right)$} \\
\hline & & \multirow[b]{2}{*}{ pure calculated $^{b}$} & \multirow[b]{2}{*}{ pure } & \multicolumn{3}{|c|}{ adsorptions } & \multicolumn{4}{|c|}{ desorptions } \\
\hline & & & & I & II & III & RT & $100{ }^{\circ} \mathrm{C}$ & $200{ }^{\circ} \mathrm{C}$ & $500{ }^{\circ} \mathrm{C}$ \\
\hline \multirow[t]{4}{*}{ zeolite } & $\nu \mathrm{Al}-\mathrm{OH}$ near $\mathrm{SiOH}$ & & 3783 & 3783 & & & & & & 3778 \\
\hline & $\nu \mathrm{Si}-\mathrm{OH}$ terminal & & 3746 & 3746 & 3746 & 3746 & 3745 & 3744 & 3744 & 3742 \\
\hline & $\nu \mathrm{Al}-\mathrm{OH}$ extra-framework $\mathrm{Al}$ & & 3667 & 3668 & 3668 & & & & 3663 & 3661 \\
\hline & $\nu \mathrm{Si}-\mathrm{OH}-\mathrm{Al}$ bridging framework & & 3610 & 3610 & 3607 & & & & 3608 & 3603 \\
\hline \multirow[t]{24}{*}{$\mathrm{EDB}$} & H-bondend silanols & & & & 3535 & 3459 & 3487 & 3531 & & \\
\hline & $\nu$ sym ip $\mathrm{C}-\mathrm{H}$ & 3075 & 3091 & & & & & & & \\
\hline & $\nu$ asym ip $\mathrm{C}-\mathrm{H}$ & 3066 & 3076 & & 3078 & 3078 & 3078 & 3078 & & \\
\hline & $\nu$ sym op $\mathrm{C}-\mathrm{H}$ & 3059 & 3062 & & & 3065 & 3066 & & & \\
\hline & $\nu$ asym op $\mathrm{C}-\mathrm{H}$ & 3049 & 3043 & & 3047 & 3047 & 3047 & 3048 & & \\
\hline & $\nu$ asym op $\mathrm{CH}_{2}$ & 3012 & 2980 & 2984 & 2980 & 2980 & 2981 & 2984 & & \\
\hline & $\nu$ asym ip $\mathrm{CH}_{2}$ & 3010 & 2934 & 2940 & 2936 & 2936 & 2937 & 2941 & & \\
\hline & $\nu$ sym ip $\mathrm{CH}_{2}$ & 3923 & 2879 & 2886 & 2883 & 2883 & 2884 & 2887 & & \\
\hline & polydentate & & & & 1708 & 1708 & 1708 & 1704 & & \\
\hline & polydentate & & & 1676 & 1693 & 1693 & 1691 & 1690 & 1675 & \\
\hline & $\nu \mathrm{C}-\mathrm{C}$ benzene $+\nu$ asym $\mathrm{CCO}$ & 1574 & 1605 & & 1608 & 1608 & 1608 & 1609 & & \\
\hline & $\nu \mathrm{C}-\mathrm{C}$ benzene & 1552 & 1594 & & 1596 & 1596 & 1596 & 1598 & 1592 & \\
\hline & $\nu \mathrm{C}-\mathrm{C}$ benzene $+\nu$ sym $\mathrm{CCO}$ & 1459 & 1495 & 1496 & 1496 & 1496 & 1496 & 1496 & 1496 & \\
\hline & $\delta_{\text {s }}$ ip $\mathrm{CH}_{2}$ & 1435 & 1467 & 1467 & 1467 & 1467 & 1467 & 1468 & 1468 & \\
\hline & $\omega$ ip $\mathrm{C}-\mathrm{H}$ & 1413 & 1453 & 1453 & 1454 & 1454 & 1454 & 1454 & & \\
\hline & polydentate & & & & 1419 & 1419 & 1419 & 1415 & & \\
\hline & $\nu \mathrm{C}-\mathrm{C}$ benzene & 1394 & 1381 & & & & & & & \\
\hline & polydentate & & & 1370 & 1370 & 1371 & 1370 & 1364 & 1362 & \\
\hline & $\omega$ op $\mathrm{CH}_{2}$ & 1359 & 1309 & & 1308 & 1308 & 1308 & 1307 & & \\
\hline & $\tau$ ip $\mathrm{CH}_{2}$ & 1263 & 1279 & & & & & & & \\
\hline & $\nu$ sym $\mathrm{C}-\mathrm{O}-\mathrm{C}$ & 1234 & 1251 & & & & & & & \\
\hline & $\nu$ asym $\mathrm{C}-\mathrm{O}-\mathrm{C}$ & 1162 & 1194 & & & & & & & \\
\hline & $\omega$ op, op' $\mathrm{C}-\mathrm{H}$ & 1112 & 1150 & & & & & & & \\
\hline & $\omega$ ip, op' $\mathrm{C}-\mathrm{H}$ & 1080 & 1112 & & & & & & & \\
\hline
\end{tabular}

${ }^{a}$ Abbreviations: $\nu$, stretching; $\omega$, wagging; $\tau$, twisting; $\delta$ s, scissoring; $\rho$, rockin; ip, in phase; op, out of phase. ${ }^{b}$ Calculated at MP2(FC) level using the $6311 \mathrm{G}(\mathrm{d}, \mathrm{p})$ basis set by the Gaussian 09 software package. ${ }^{40}$ IR frequencies were scaled by a factor of $0.9496 .{ }^{41}{ }^{c}$ Pure gas phase molecule. 


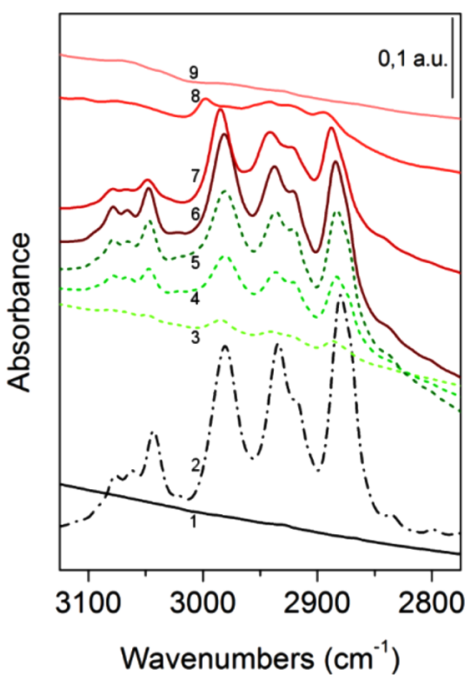

Figure 8. FTIR spectra, in the $\mathrm{C}-\mathrm{H}$ stretching region, of increasing dosages of EDB on H-BEA followed by evacuation at increasing temperatures. (1) Solid black spectrum, H-BEA calcined at $500{ }^{\circ} \mathrm{C}$ for $6 \mathrm{~h}$; (2) dashed-dotted black spectrum, pure EDB; dashed green scale spectra, adsorption of EDB at RT (3) low, (4) medium, and (5) high coverages; solid red scale spectra, desorption steps at increasing temperatures (6) RT, (7) $100{ }^{\circ} \mathrm{C}$, (8) $200{ }^{\circ} \mathrm{C}$, and (9) $500{ }^{\circ} \mathrm{C}$.

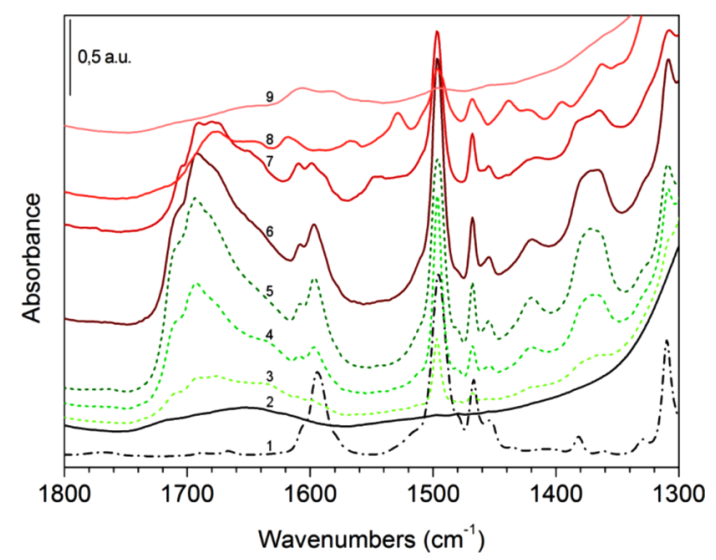

Figure 9. FTIR spectra, in the region $1800-1300 \mathrm{~cm}^{-1}$, of increasing dosages of EDB on H-BEA followed by evacuation at increasing temperature. (1) Solid black spectrum, H-BEA calcined at $500{ }^{\circ} \mathrm{C}$ for $6 \mathrm{~h}$; (2) dashed-dotted black spectrum, pure EDB; dashed green scale spectra, adsorption of EDB at RT (3) low, (4) medium and (5) high coverages; solid red scale spectra, desorption steps at increasing temperatures (6) RT, (7) $100{ }^{\circ} \mathrm{C}$, (8) $200{ }^{\circ} \mathrm{C}$, and (9) $500{ }^{\circ} \mathrm{C}$.

such as observed by Lavalley ${ }^{63}$ and Wirawan et al. ${ }^{64}$ These last results confirm that $\mathrm{EDB}$ interacts predominately through the benzene ring and methylene group instead of oxygen, maintaining a planar conformation.

The adsorption of EDB on alumina (Figure 10) confirm the hypothesis of its planar adsorption. In particular the appearance of the bands at 1701, 1690,1423, and $1368 \mathrm{~cm}^{-1}$ confirm the formation of the bicoordinated adduct. Also in this case phenate species strongly adsorbed on alumina are formed, such as confirmed by the presence of bands at 1592 and $1496 \mathrm{~cm}^{-1}$ and in the region $1320-1220 \mathrm{~cm}^{-1}$.62

Interaction of DEB with Zeolite. DEB shows both kinds of interaction already observed separately for EDB and MDB; Table 4 summarizes these results. In particular, as observed for $\mathrm{MDB}$, the formation of a strong H-bond between ether groups

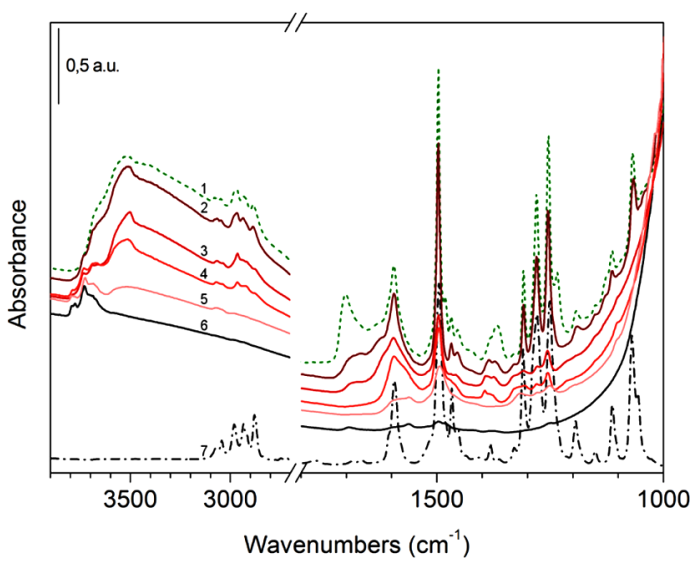

Figure 10. Changes in FTIR spectra of $\gamma-\mathrm{Al}_{2} \mathrm{O}_{3}$ produced by adsorption of EDB followed by desorption at increasing temperatures. (1) green dashed spectrum, adsorbed EDB; solid red scale spectra, desorption steps at increasing temperatures (2) RT, (3) $100{ }^{\circ} \mathrm{C}$, (4) $200{ }^{\circ} \mathrm{C}$, and (5) $500{ }^{\circ} \mathrm{C}$; (6) solid black spectrum, $\gamma-\mathrm{Al}_{2} \mathrm{O}_{3}$ after evacuation at $500{ }^{\circ} \mathrm{C}$ for $6 \mathrm{~h}$; (7) dashed-dotted black black spectrum, pure EDB.

and zeolite hydroxyls leads to the erosion of the two bands at 3779 and $3741 \mathrm{~cm}^{-1}$ and the simultaneous formation of a broad band centered at $3469 \mathrm{~cm}^{-1} \cdot 26,56-59$ The shoulder at $3588 \mathrm{~cm}^{-1}$ is ascribable to the perturbation of H-bonded silanols caused by interaction with the benzene ring, as previously evidenced for EDB (Figure 11). ${ }^{24,25}$ The absence of an additional fused ring, which forces the molecule to stay in a preferential conformation, leads DEB to interact simultaneously by the oxygen atoms and the benzene ring. Also in this case the two components of Fermi resonance ( $\mathrm{A}$ and $\mathrm{B})$ may be observed respectively at 2960 and $2440 \mathrm{~cm}^{-1}$ (Figure 11). ${ }^{26,54,57,60}$

As shown in Figure 12, peaks attributed to aromatic moiety are shifted slightly upward, such as in the case of EDB, suggesting that a planar adsorption of the benzene ring occurs on zeolite, as confirmed by benzene $\mathrm{C}-\mathrm{C}$ stretchings at 1506 and $1592 \mathrm{~cm}^{-1}$, also perturbed (Figure 13).

Aliphatic $\mathrm{C}-\mathrm{H}$ stretching bands are shifted to higher frequencies and, as in the adsorption of $\mathrm{MDB}$, a splitting of the component at $2954 \mathrm{~cm}^{-1}$ is observed (Figure 12). This latter result may be attributed to the interaction between the hydrogens of the methyl groups and the oxygens of the zeolite framework. Therefore, the $\mathrm{CH}_{3}$ deformation bands at 1463 and $1442 \mathrm{~cm}^{-1}$ also result in a shift to higher wavenumbers. The only partial disappearance of DEB signals, even after desorption at $500{ }^{\circ} \mathrm{C}$, indicates its strong interaction with the zeolite, as in case of MDB..$^{27,54,55}$ As expected from previous considerations on EDB, the bands at 1694 (shoulder at $1710 \mathrm{~cm}^{-1}$ ), 1420, and $1368 \mathrm{~cm}^{-1}$ grow due to the formation of polydentate species ${ }^{63,64}$ due to the interaction between $\mathrm{CH}_{3}$ and zeolite oxygen.

Final Remarks. Comparing the data obtained in the catalytic tests with the spectroscopic data it is possible to propose different modes of adsorption of the aromatic substrates on considered materials. In the case of MDB the FT-IR findings show that the interaction occurs almost exclusively between hydroxyl groups of the catalyst and oxygen atoms of the substrate, thus the adsorbed MDB molecule maintains the puckered conformation, as shown in Figure 14 for zeolite. Figure 15 shows the hypothesized model for the adsorption of EDB on zeolite, for which the twisted geometry 
Table 4. Vibrational Assignments $\left(\mathrm{cm}^{-1}\right)$ for $\mathrm{DEB}^{a}$

\begin{tabular}{|c|c|c|c|c|c|c|c|c|c|}
\hline & \multirow[b]{3}{*}{ description } & \multicolumn{8}{|c|}{ wavenumbers $\left(\mathrm{cm}^{-1}\right)$} \\
\hline & & \multirow[b]{2}{*}{ pure calculated $^{b}$} & \multirow[b]{2}{*}{ pure } & \multicolumn{2}{|c|}{ adsorptions } & \multicolumn{4}{|c|}{ desorptions } \\
\hline & & & & I & II & $\mathrm{RT}$ & $100{ }^{\circ} \mathrm{C}$ & $200{ }^{\circ} \mathrm{C}$ & $500{ }^{\circ} \mathrm{C}$ \\
\hline \multirow[t]{4}{*}{ zeolite } & $\nu \mathrm{Al}-\mathrm{OH}$ near $\mathrm{SiOH}$ & & 3779 & & & & & & 3778 \\
\hline & $\nu \mathrm{Si}-\mathrm{OH}$ terminal & & 3741 & 3745 & & & 3744 & 3743 & 3741 \\
\hline & $\nu \mathrm{Al}-\mathrm{OH}$ extraframework $\mathrm{Al}$ & & 3661 & & & & & & 3662 \\
\hline & $\nu \mathrm{Si}-\mathrm{OH}-\mathrm{Al}$ bridging framework & & 3603 & & & & & & 3601 \\
\hline \multirow[t]{29}{*}{$\mathrm{DEB}$} & H-bondend silanols & & & 3588 & 3584 & 3592 & 3598 & & \\
\hline & H-bonded complex & & & 3469 & 3462 & 3464 & 3493 & 3532 & \\
\hline & $\nu$ sym ip $\mathrm{C}-\mathrm{H}$ & 3087 & 3107 & 3109 & 3011 & 3113 & 3113 & & \\
\hline & $\nu$ sym ip $\mathrm{C}-\mathrm{H}$ & 3084 & 3078 & & & & & & \\
\hline & $\nu$ asym op $\mathrm{C}-\mathrm{H}$ & 3065 & 3064 & 3070 & 3068 & 3069 & 3073 & 3072 & 3065 \\
\hline & $\nu$ sym op $\mathrm{C}-\mathrm{H}$ & 3049 & 3045 & 3047 & 3048 & 3049 & 3049 & & \\
\hline & $\nu$ asym ip $\mathrm{CH}_{3}$ & 3039 & 3000 & 3004 & 3002 & 3002 & 3007 & 3005 & \\
\hline & $\nu$ asym op $\mathrm{CH}_{3}(\mathrm{CH} \cdots \mathrm{OSi})$ & 2971 & 2954 & 2967 & 2967 & 2967 & 2968 & 2963 & \\
\hline & $\nu \mathrm{CH}_{3}$ & & 2944 & 2947 & 2947 & 2949 & 2952 & & \\
\hline & $\nu \mathrm{CH}_{3}$ & & 2934 & 2936 & & & & & \\
\hline & $\nu \mathrm{CH}_{3}$ & & 2906 & 2912 & 2912 & 2912 & 2918 & & \\
\hline & $\nu \mathrm{CH}_{3}$ & & 2889 & 2892 & 2892 & 2893 & 2898 & & \\
\hline & $\nu$ sym op $\mathrm{CH}_{3}$ & 2898 & 2835 & 2842 & 2840 & 2840 & 2846 & & \\
\hline & polydentate & & & 1710 & 1710 & 1710 & 1710 & & \\
\hline & polydentate & & & 1694 & 1694 & 1694 & 1673 & 1670 & \\
\hline & $\nu \mathrm{C}-\mathrm{C}$ benzene $+\nu$ asym $\mathrm{CCO}$ & 1563 & 1592 & 1596 & 1595 & 1595 & 1599 & 1599 & 1598 \\
\hline & $\nu \mathrm{C}-\mathrm{C}$ benzene $+\nu$ asym $\mathrm{CCO}$ & 1480 & 1506 & 1505 & 1500 & 1500 & 1504 & 1504 & \\
\hline & $\delta_{\mathrm{s}} \mathrm{HCH}(\mathrm{CH} 3)$ & 1457 & 1463 & 1466 & 1465 & 1465 & 1468 & 1468 & \\
\hline & $\delta_{\mathrm{s}} \mathrm{HCH}(\mathrm{CH} 3)$ & 1435 & 1442 & 1444 & 1444 & 1444 & 1446 & & \\
\hline & polydentate & & & 1420 & 1420 & & & & \\
\hline & polydentate & & & 1368 & 1364 & 1363 & & & \\
\hline & $\delta_{\text {umbrella }} \mathrm{CH}_{3}$ & 1421 & 1330 & & 1327 & 1326 & & & \\
\hline & $\delta_{\text {umbrella }} \mathrm{CH}_{3}$ & 1399 & 1286 & & & & & & \\
\hline & $\nu_{\text {sym }} \mathrm{PhO}+\nu \mathrm{C}-\mathrm{C}+\mathrm{CH}$ in plane bend & 1255 & 1254 & & & & & & \\
\hline & $\nu_{\text {asym }} \mathrm{PhO}+\nu \mathrm{C}-\mathrm{C}+\mathrm{CH}$ in plane bend & 1211 & 1230 & & & & & & \\
\hline & $\rho \mathrm{CH}_{3}$ & 1157 & 1176 & & & & & & \\
\hline & $\mathrm{CH}$ in plane bending & 1096 & 1123 & & & & & & \\
\hline & $\nu$ sym $\mathrm{O}-\mathrm{CH}_{3}$ & 1042 & 1052 & & & & & & \\
\hline & $\nu$ sym $\mathrm{O}-\mathrm{CH}_{3}$ & 1019 & 1028 & & & & & & \\
\hline
\end{tabular}

${ }^{a}$ Abbreviations: $\nu$, stretching; $\omega$, wagging; $\tau$, twisting; $\delta$ s, scissoring; $\rho$, rockin; ip, in phase; op, out of phase. ${ }^{b}$ Calculated at MP2(FC) level using the $6311 \mathrm{G}(\mathrm{d}, \mathrm{p})$ basis set by the Gaussian 09 software package. ${ }^{40}$ IR frequencies were scaled by a factor of $0.9496 .{ }^{41}{ }^{c}$ Pure gas phase molecule.

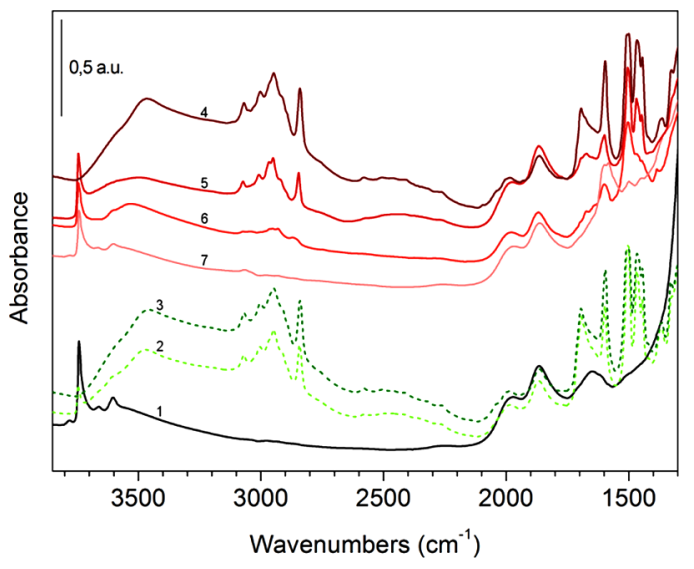

Figure 11. FTIR spectra of increasing dosages of DEB on H-BEA followed by evacuation at increasing temperature. (1) Solid black spectrum, H-BEA calcined at $500{ }^{\circ} \mathrm{C}$ for $6 \mathrm{~h}$; dashed green scale spectra, adsorption of DEB at RT (2) medium and (3) high coverages; solid red scale spectra, desorption steps at increasing temperature (4) RT, (5) $100{ }^{\circ} \mathrm{C},(6) 200{ }^{\circ} \mathrm{C}$, and (7) $500{ }^{\circ} \mathrm{C}$. of the molecule is suitable for a planar linkage through benzene ring and the methylene group without involving the oxygen atom. Also, in this case, the configuration of the free molecule is maintained after adsorption. The conformational mobility of free methoxy groups allows DEB molecule to maintain a planar geometry during the adsorption, with simultaneous interaction through oxygen atoms and benzene ring, as demonstrated by FT-IR analysis.

The above results may be useful in clarifying the different reactivity previously observed in the catalytic tests. All three investigated substrates were reactive in homogeneous conditions, in which geometrical conformational changes may occur. On the contrary, the same behavior is not possible using heterogeneous catalysts, on which the molecules are forced to maintain a specific conformation.

The planar orientation in case of EDB and DEB leads the molecules to react with activated alkylating agents. Conversely, in the case of MDB the molecule remains in the puckered conformation thus the aromatic ring is electron-deficient, then deactivated, because the oxygen p-orbital can interact predominantly with the methylene group orbital as reported 


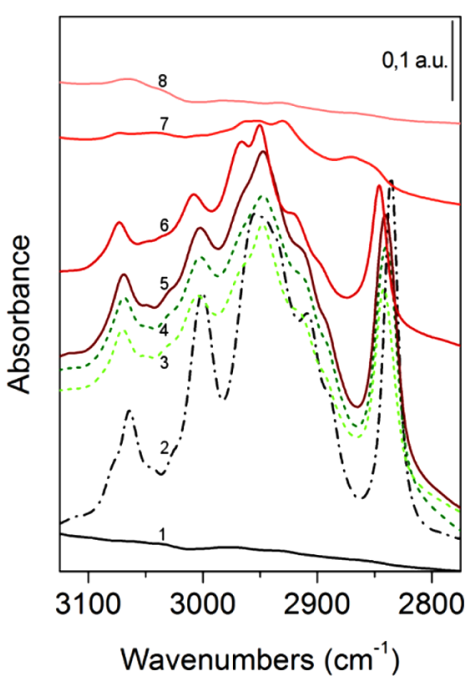

Figure 12. FTIR spectra, in the $\mathrm{C}-\mathrm{H}$ stretching region, of increasing dosages of DEB on H-BEA followed by evacuation at increasing temperatures. (1) solid black spectrum, H-BEA calcined at $500{ }^{\circ} \mathrm{C}$ for $6 \mathrm{~h}$; (2) dashed-dotted black spectrum, pure DEB; dashed green scale spectra, adsorption of DEB at RT (3) medium and (4) high coverages; solid red scale spectra, desorption steps at increasing temperature (5) RT, (6) $100{ }^{\circ} \mathrm{C}$, (7) $200{ }^{\circ} \mathrm{C}$, and (8) $500{ }^{\circ} \mathrm{C}$.

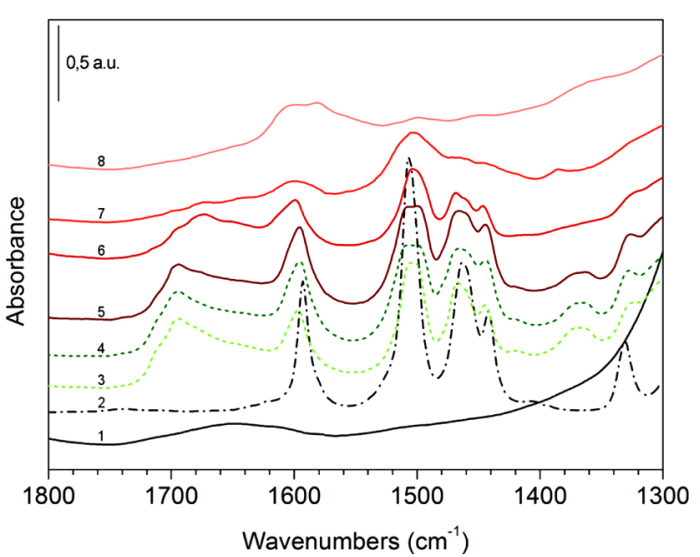

Figure 13. FTIR spectra, in the region $1800-1300 \mathrm{~cm}^{-1}$, of increasing dosages of DEB on H-BEA followed by evacuation at increasing temperatures. (1) Solid black spectrum, H-BEA calcined at $500{ }^{\circ} \mathrm{C}$ for $6 \mathrm{~h}$; (2) dashed-dotted black spectrum, pure DEB; dashed green scale spectra, adsorption of DEB at RT (3) medium and (4) high coverages; solid red scale spectra, desorption steps at increasing temperatures (5) $\mathrm{RT}$, (6) $100{ }^{\circ} \mathrm{C}$, (7) $200{ }^{\circ} \mathrm{C}$, and (8) $500{ }^{\circ} \mathrm{C}$.

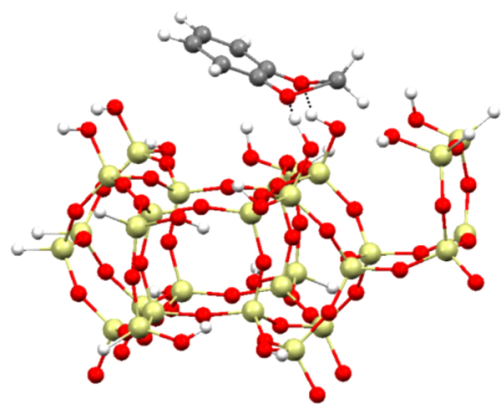

Figure 14. Proposed model for MDB adsorption on beta zeolite.

by Moon. ${ }^{61}$ This effect deactivates the benzene ring resulting in a complete chemical inertia of MDB on tested catalysts.

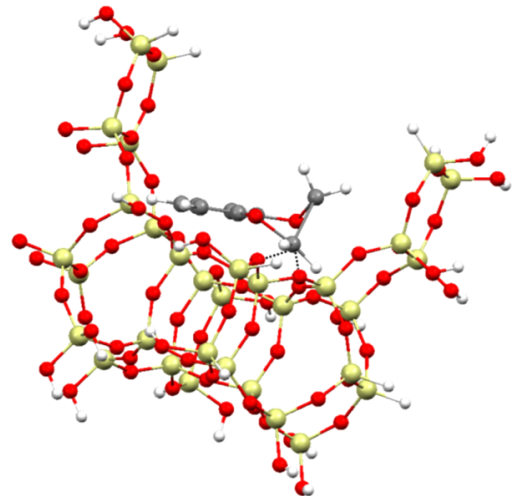

Figure 15. Proposed model for EDB adsorption on beta zeolite.

\section{CONCLUSION}

A deep FT-IR investigation of the adsorption and desorption behavior of methoxy substituted benzenes (MDB, EDB, and DEB) on two different acid catalysts (zeolite BEA and $\gamma$ alumina) allowed to elucidate the relevant differences observed between MDB with the other aromatic substrates (EDB and DEB). The FT-IR analysis were supported by computational geometry investigation.

1. The ab initio calculation showed different lowest-energy conformation for the three aromatic substrates studied, in particular puckered for $\mathrm{MDB}$, twisted for $\mathrm{EDB}$ and anti-anti for DEB. These results was experimentally confirmed by FT-IR spectroscopy; in fact, the calculated frequencies are in agreement with the experimental ones. In the case of DEB the calculated bands are quite different from the experimental ones because the simulation has been done only for the lowest energy conformer.

2. The IR spectra demonstrated that adsorbed molecules maintained the geometry of the free ones.

3. The twisted conformation of EDB and anti-anti of DEB allow the aromatic ring to be planar and suited for electrophilic attack during adsorption.

4. MDB adsorption through oxygen atoms holds the molecule in the puckered conformation, maintaining the benzene ring electron-deficient, then deactivated toward electrophilic alkylation.

5. The obtained results of the reactivity of $\mathrm{MDB}$ in a homogeneous catalytic systems $\left(\mathrm{AlCl}_{3}\right.$ and $\left.\mathrm{H}_{2} \mathrm{SO}_{4}\right)$ may be explained by the conformational change which is possible in these conditions while not in a heterogeneous one.

\section{AUTHOR INFORMATION}

\section{Corresponding Author}

*Tel.: +39051 209 3683. E-mail: angelo.vaccari@unibo.it.

Notes

The authors declare no competing financial interest.

\section{REFERENCES}

(1) Patinkin, S. H.; Friedman, B. S. In Friedel-Crafts and Related Reactions; Olah, G. A., Ed.; Wiley: New York, 1964; Vol. 2.

(2) Hoelderich, W. F. Catal. Today 2000, 62, 115-130.

(3) Tanabe, K.; Hölderich, W. F. Appl. Catal., A 1999, 181, 399-434.

(4) Degnan; Thomas, F., J.; Smith, C. M.; Venkat, C. R. Appl. Catal., A 2001, 221, 283-294. 
(5) Siffert, S.; Gaillard, L.; Su, B.-L. J. Mol. Catal. A: Chem. 2000, 153, 267-279.

(6) Perego, C.; Ingallina, P. Catal. Today 2002, 73, 3-22.

(7) Čejka, J.; Wichterlová, B.; Bednářová, S. Appl. Catal., A 1991, 79, 215-226.

(8) Brechtelsbauer, C.; Emig, G. Appl. Catal., A 1997, 161, 79-92.

(9) Ahedi, R. K.; Tawada, S.; Kubota, Y.; Sugi, Y.; Kim, J. H. J. Mol. Catal. A: Chem 2003, 197, 133-146.

(10) Sugi, Y.; Kubota, Y.; Hanaoka, T.-aki; Matsuzaki, T. Catal. Surv. Jpn. 2001, 5, 43-56.

(11) Bejblová, M.; Žilková, N.; Čejka, J. Res. Chem. Intermed. 2008, 34, 439-454.

(12) Giugni, A.; Impalà, D.; Piccolo, O.; Vaccari, A.; Corma, A. Appl. Catal., B 2010, 98, 72-78.

(13) Vanelle, P.; Meuche, J.; Maldonado, J.; Crozet, M. P.; Delmas, F.; Timon-David, P. Eur. J. Med. Chem. 2000, 35, 157-162.

(14) Borzatta, V.; Capparella, E.; Gobbi, C.; Poluzzi, E. Process for synthesizing heliotropine and its derivatives. U.S. Patent 7,402,709, 2008.

(15) Kushiro, M.; Masaoka, T.; Hageshita, S.; Takahashi, Y.; Ide, T.; Sugano, M. J. Nutr. Biochem. 2002, 13, 289-295.

(16) Spagnol, M.; Gilbert, L.; Benazzi, E.; Marcilly, C. Process for the acylation of aromatic ethers. U.S. Patent 5,817,878, 1998.

(17) Scriabine, I. Bull. Soc. Chim. Fr. 1961, 1197-1198.

(18) Valentine, R. H.; Brandman, H. A. Process for the preparation of dihydrocinnamaldehyde derivates, U.S. Patent 4,389,527, 1983.

(19) Shirai, M.; Yoshida, Y.; Sadaike, S. Process for the production of 1acetoxy-3-(substituted phenyl)propenes, E.P. Patent 1,574,509 (A1), 2005.

(20) Snowden, R.; Birkbeck, A.; Womack, G.; Firmenich S. A. Catalytic Scriabine reaction, U.S. Patent 7,529,983 (B2), 2009.

(21) Borzatta, V.; Brancaleoni, D. Process for the synthesis of 5- $(\alpha-$ hydroxyalkyl)benzo[1,3]dioxols, U.S. Patent 6,342,613, 2000.

(22) Borzatta, V.; Brancaleoni, D.; Battistini, C. Process for the synthesis of 5-alkylbenzodioxoles, E.P. Patent 1,048,664 (B1), 2000.

(23) Zelle, R. E.; McClellan, W. J. Tetrahedron Lett. 1991, 32, 24612464.

(24) Su, B.-L.; Norberg, V. Zeolites 1997, 19, 65-74.

(25) Kiricsi, I.; Flego, C.; Pazzuconi, G.; Parker, W.O., J.; Millini, R.; Perego, C.; Bellussi, G. J. Phys. Chem. 1994, 98, 4627-4634.

(26) Pazé, C.; Bordiga, S.; Lamberti, C.; Salvalaggio, M.; Zecchina, A.; Bellussi, G. J. Phys. Chem. B 1997, 101, 4740-4751.

(27) Bjørgen, M.; Bonino, F.; Kolboe, S.; Lillerud, K.-P.; Zecchina, A.; Bordiga, S. J. Am. Chem. Soc. 2003, 125, 15863-15868.

(28) Namuangruk, S.; Pantu, P.; Limtrakul, J. J. Catal. 2004, 225, $523-530$.

(29) Rungsirisakun, R.; Jansang, B.; Pantu, P.; Limtrakul, J. J. Mol. Struct. 2005, 733, 239-246.

(30) Trombetta, M.; Alejandre, A. G.; Solis, J. R.; Busca, G. Appl. Catal., A 2000, 198, 81-93.

(31) Raksakoon, C.; Limtrakul, J. J. Mol. Struct.: THEOCHEM 2003, 631, 147-156.

(32) Trombetta, M.; Armaroli, T.; Alejandre, A. G.; Solis, J. R.; Busca, G. Appl. Catal., A 2000, 192, 125-136.

(33) Ballarini, N.; Cavani, F.; Maselli, L.; Montaletti, A.; Passeri, S.; Scagliarini, D.; Flego, C.; Perego, C. J. Catal. 2007, 251, 423-436.

(34) Ballarini, N.; Cavani, F.; Maselli, L.; Passeri, S.; Rovinetti, S. J. Catal. 2008, 256, 215-225.

(35) Cavani, F.; Maselli, L.; Passeri, S.; Lercher, J. A. J. Catal. 2010, 269, 340-350.

(36) Crocellà, V.; Cerrato, G.; Magnacca, G.; Morterra, C.; Cavani, F.; Maselli, L.; Passeri, S. Dalton Trans. 2010, 39, 8527-8537.

(37) Svelle, S.; Bjørgen, M. J. Phys. Chem. A 2010, 114, 1254812554 .

(38) Svelle, S.; Visur, M.; Olsbye, U.; Saepurahman; Bjørgen, M. Top. Catal. 2011, 54, 897-906.

(39) Bjorgen, M.; Svelle, S.; Joensen, F.; Nerlov, J.; Kolboe, S.; Bonino, F.; Palumbo, L.; Bordiga, S.; Olsbye, U. J. Catal. 2007, 249, 195-207.
(40) Frisch, M. J.; Trucks, G. W.; Schlegel, H. B.; Scuseria, G. E.; Robb, M. A.; Cheeseman, J. R; Scalmani, G.; Barone, V.; Mennucci, B.; Petersson, G. A.; Nakatsuji, H. et al. Gaussian 09, revision B.01; Gaussian, Inc.: Wallingford, CT, 2010.

(41) Scott, A. P.; Radom, L. J. Phys. Chem. 1996, 100, 16502-16513.

(42) Perego, C.; Amarilli, S.; Carati, A.; Flego, C.; Pazzuconi, G.; Rizzo, C.; Bellussi, G. Microporous Mesoporous Mater. 1999, 27, 345354.

(43) Amandi, R.; Licence, P.; Ross, S. K.; Aaltonen, O.; Poliakoff, M. Org. Process Res. Dev. 2005, 9, 451-456.

(44) Dorofeeva, O. V.; Shishkov, I. F.; Karasev, N. M.; Vilkov, L. V.; Oberhammer, H. J. Mol. Struct. 2009, 933, 132-141.

(45) Emanuele, E.; Negri, F.; Orlandi, G. Chem. Phys. 2006, 321, 7585.

(46) Jeon, S.; Choo, J.; Kim, S.; Kwon, Y.; Kim, J.-Y.; Lee, Y.-I.; Chung, H. J. Mol. Struct. 2002, 609, 159-167.

(47) Autrey, D.; Yang, J.; Laane, J. J. Mol. Struct. 2003, 661-662, 2332

(48) Novikov, V. P.; Yarkov, A. V.; Solotnov, A. F.; Raevskii, O. A. Russ. Chem. Bull. 1985, 34, 952-958.

(49) Digne, M.; Sautet, P.; Raybaud, P.; Euzen, P.; Toulhoat, H. J. Catal. 2002, 211, 1-5.

(50) Tsyganenko, A. A.; Filimonov, V. N. J. Mol. Struct. 1973, 19, $579-589$.

(51) Morterra, C.; Magnacca, G. Catal. Today 1996, 27, 497-532.

(52) M. Haaland, D. Surf. Sci. 1981, 102, 405-423.

(53) Ballinger, T. H.; Yates, J. T. J. Langmuir 1997, 3041-3045.

(54) Bregolato, M.; Bolis, V.; Busco, C.; Ugliengo, P.; Bordiga, S.; Cavani, F.; Ballarini, N.; Maselli, L.; Passeri, S.; Rossetti, I.; Forni, L. J. Catal. 2007, 245, 285-300.

(55) Flego, C.; Kiricsi, I.; Perego, C.; Bellussi, G. Stud. Surf. Sci. Catal. 1995, 405-412.

(56) Skorpa, R.; Bordiga, S.; Bleken, F.; Olsbye, U.; Arstad, B.; Tolchard, J.; Mathisen, K.; Svelle, S.; Bjørgen, M. Microporous Mesoporous Mater. 2011, 141, 146-156.

(57) Zecchina, A.; Spoto, G.; Ricchiardi, G.; Bordiga, S.; Bonino, F.; Prestipino, C.; Lamberti, C. In Impact of Zeolites and other Porous Materials on the new Technologies at the Beginning of the New Millennium Proceedings of the 2nd International FEZA (Federation of the European Zeolite Associations) Conference; Aiello, R., Giordano, G., Testa, F., Eds.; Elsevier: Amsterdam, The Netherlands, 2002; Vol. 142, pp 3-14.

(58) Bordiga, S.; Regli, L.; Cocina, D.; Lamberti, C.; Bjørgen, M.; Lillerud, K. P. J. Phys. Chem. B 2005, 109, 2779-2784.

(59) Barbera, K.; Bonino, F.; Bordiga, S.; Janssens, T. V. W.; Beato, P. J. Catal. 2011, 280, 196-205.

(60) Trombetta, M.; Busca, G.; Storaro, L.; Lenarda, M.; Casagrande, M.; Zambon, A. Phys. Chem. Chem. Phys. 2000, 2, 3529-3537.

(61) Moon, S.; Kwon, Y.; Lee, J.; Choo, J. J. Phys. Chem. A 2001, 105, 3221-3225.

(62) Popov, A.; Kondratieva, E.; Goupil, J. M.; Mariey, L.; Bazin, P.; Gilson, J.-P.; Travert, A.; Maugé, F. J. Phys. Chem. C 2010, 114, 15661-15670.

(63) Lavalley, J. C. Catal. Today 1996, 27, 377-401.

(64) Wirawan, S. K.; Creaser, D. Microporous Mesoporous Mater. 2006, 91, 196-205. 